\title{
KNOWLEDGE, ATTITUDE AND PRACTICE TOWARDS HIV/AIDS IN A RURAL KENYAN COMMUNITY
}

\author{
MOHAMED KARAMA*†, TARO YAMAMOTO + , MASAAKI SHIMADA§, \\ S. S. A. ORAGO* AND KAZUHIKO MOJI§ \\ * School of Health Sciences, Kenyatta University, Kenya, †Center for Public Health \\ Research, Kenya Medical Research Institute, Kenya, $\$$ Division of Aid Planning, \\ Economic Cooperation Bureau, Ministry of Foreign Affairs and §Research Center for \\ Tropical Infectious Diseases, Institute of Tropical Medicine, Nagasaki University, \\ Japan
}

\begin{abstract}
Summary. The aim of this research was to explore people's knowledge, attitude, behaviour and practice towards HIV/AIDS and sexual activity in rural Kenya, where HIV is widespread. The study community was located in south-eastern Kenya, $50 \mathrm{~km}$ north of Mombassa, and had an estimated population of 1500 . Subjects aged between 16 and 49 were recruited using a stratified cluster-sampling method and they completed self-administered questionnaires.Almost all respondents knew the word 'HIV'. Around 50\% knew of a person living with HIV. About $80 \%$ gave 'death' or 'fear' as words representing their image of AIDS. With regard to sexual activity, the distribution of answers to the question 'how many partners have you ever had in your life' was bimodal in males but had only one peak in females, indicating that some men have a large number of sexual partners in their lifetime. First sexual intercourse was at around 12-13 years for both sexes, but female teenagers were more sexually experienced than their male counterparts.
\end{abstract}

\section{Introduction}

As of the end of 2003 there were an estimated 42 million people living with HIV/AIDS worldwide, and about three million were dying of AIDS each year. HIV is now the single largest infectious killer virus and AIDS is the fourth leading cause of death in the world and the second in sub-Saharan Africa. Sub-Saharan Africa is the part of the world most severely affected by HIV/AIDS, and this shows little sign of weakening (UNAIDS \& WHO, 2004). Although life expectancy at birth rose from about 40 years to 63 between 1950 and 1990 in that region, this has been erased by the HIV/AIDS epidemic and life expectancy is back to what it was 50 years ago (World Bank, 1999). The same has happened in Kenya, where the HIV/AIDS 
epidemic has left many orphans and HIV-infected infants, resulting in an 11-year decline in life expectancy at birth in Kenya.

Kenya is now in the process of a demographic transition and about $40 \%$ of the population now live in urban areas, which tend to have a high prevalence of HIV infection. However, current statistics in Kenya show that rural communities are as severely affected by HIV as are urban communities. For instance, at Tiwi hospital in Kwale District, which is the next town to where this study was conducted, the prevalence of HIV among pregnant women and STI patients was $15 \cdot 4 \%$ and $23.6 \%$, respectively, according to a national surveillance completed in 1999. This is not much lower than the $24 \cdot 6 \%$ HIV positive rate among pregnant women in Nairobi (NAPSCO, 2000).

A number of knowledge, attitude, behaviour and practice (KABP) studies have been carried out on various groups on the issue of HIV and sexual-related matters (Mbanya et al., 2001; Mbago \& Sichona, 2003). In Kenya, such studies have involved commercial sex worker, AIDS patients and university students, but very few have focused on people in the community (Karani et al., 1990; Katsivo \& Muthami, 1991; Barker, 1993; Sindiga \& Lukhando, 1993; Kaimenyi \& Ndung'u, 1994; Pattullo et al., 1994; Obudho, 1995). However, in order to plan an STI and HIV/AIDS related project, it is important to understand the knowledge, attitude and practice of the study population.

In a village of Kwale District, staff at the Kenya Medical Research Institute (KEMRI) and ex-JICA (Japanese International Cooperation Agency) experts are turning their attention to the prevention of sexually transmitted infections, including HIV/AIDS, which are highly prevalent in the area. As a first step, it was considered important to assess knowledge, attitude, behaviour and practice towards sexually transmitted infections including HIV/AIDS. Thus it was decided to conduct a KABP survey in order to provide the basis for future STI and HIV/AIDS prevention projects.

\section{Methods}

\section{Study area and population}

The study area is mountainous and not easy to access, even by bus due to the steep mountain road. The area is $50 \mathrm{~km}$ north of Mombassa and $10 \mathrm{~km}$ from the coast. Its population is around 1500 and the major industry is farming. While the area is known to have been a place where schistosomiasis was rampant, HIV infection is also spreading rapidly. Male seasonal workers who move back and forth between their rural homes and urban work places are likely to be the major players in the transmission of the virus (NAPSCO, 2000). Whereas most Kenyans are Christians, there is a large Muslim population in this coastal area. Many Christians and Muslims have found a way to accommodate each other's culture and religion.

Questionnaire respondents were those aged between 15 and 49 chosen using a cluster-sampling method. The target area was clustered into five sub-areas and two out of five were selected as sampling areas. People living in the sampling areas were invited to enrol in the questionnaire survey after the informed consent form had been explained to them. A member of the research team visited house to house with the help of staff from the local village health centre. The local staff member waited 
Table 1. Age distribution of questionnaire respondents

\begin{tabular}{lcc}
\hline Age group & Females & Males \\
\hline 19 & $68(50 \cdot 7 \%)$ & $46(39 \cdot 7 \%)$ \\
$20-29$ & $32(23 \cdot 8 \%)$ & $38(32 \cdot 8 \%)$ \\
$30-39$ & $18(13 \cdot 4 \%)$ & $27(23 \cdot 3 \%)$ \\
$40-49$ & $16(11 \cdot 9 \%)$ & $5(4 \cdot 3 \%)$ \\
Total & 134 & 116 \\
\hline
\end{tabular}

The average ages of the male and female respondents were $23 \cdot 5 \pm 9 \cdot 5$ and $24 \cdot 5 \pm 8 \cdot 3$, respectively.

outside the house, for ethical reasons. The total number of respondents was 250: 134 male and 116 female. The average ages of male and female respondents were $23 \cdot 5 \pm 9 \cdot 5($ mean $\pm \mathrm{SD}$ ) and $24 \cdot 5 \pm 8 \cdot 3$, respectively (Table 1$)$.

\section{The questionnaire}

The questionnaire was translated into the local language, Swahili, from the English version by KEMRI staff. The revised version of the questionnaire was delivered to those people who had given their informed consent. The questionnaire asked about demographic characteristics of the respondents such as age, sex and occupation as well as their knowledge on various aspects of HIV/AIDS and their attitude, behaviour and practice towards HIV/AIDS and sexual practice.

\section{Results}

\section{General perception of health}

In response to questions about health status, $73.9 \%$ of male respondents and $75 \cdot 2 \%$ of female respondents answered that their health status was 'very good' or 'fairly good'. As for perceptions about health, the percentage of respondents who answered that good health is mostly a matter of self-responsibility was $88 \cdot 1 \%$ among males and $91.4 \%$ among females. With regard to the question of whether maintaining good health is the most important thing in life, the percentage of respondents who gave the answer 'strongly agree' or 'agree' was $98 \cdot 5 \%$ among males and $97 \cdot 4 \%$ among females (Table 2).

\section{General knowledge about HIVIAIDS}

Questions about people's knowledge of HIV/AIDS revealed that respondents had some misunderstandings. The question, for example, 'Is HIV antibodies testing useful for confirming diagnosis even after only one week of infection?' scored the lowest correct answer rate of all, followed by the question, 'Might people infected with HIV look healthy?' The percentage of correct answers given to these two questions was less than 50\% and about 59\%, respectively. The questions 'Is HIV transmitted by 
Table 2. Knowledge, attitude and practice towards HIV/AIDS survey results

Males (\%) Females (\%)

The perception of health

Good health is mostly a matter of self-responsibility

Good health is mostly a matter of luck

Cannot choose

$\begin{array}{rr}88 \cdot 1 & 91 \cdot 4 \\ 7 \cdot 5 & 7 \cdot 8 \\ 4 \cdot 5 & 0.9\end{array}$

Maintaining good health is the most important thing in your life

Strongly agree

$56 \cdot 0$

$29 \cdot 3$

Agree

$42 \cdot 5$

$68 \cdot 1$

Disagree

0

$0 \cdot 9$

Strongly disagree

0.8

0

Cannot choose

$0 \cdot 8$

Regarding premarital sex, in general do you:

Approve

$47 \cdot 0$

$32 \cdot 8$

Disapprove

$41 \cdot 8$

$63 \cdot 8$

Have mixed feeling

$11 \cdot 2$

In which ways did you learn about sexual matters?

Parents

$4 \cdot 1$

$4 \cdot 0$

Siblings

$2 \cdot 3$

0.7

Other relatives

$5 \cdot 2$

$7 \cdot 3$

Friends

$43 \cdot 4$

$50 \cdot 1$

Lessons at school

$17 \cdot 3$

$16 \cdot 0$

TV

$12 \cdot 7$

8.7

Radio

$2 \cdot 3$

$2 \cdot 7$

Magazines

$12 \cdot 7$

$10 \cdot 0$

Do you know the word 'HIV'?

Yes

$94 \cdot 8$

$97 \cdot 4$

Do you know of anyone infected with HIV? (Yes)

$53 \cdot 0$

$56 \cdot 0$

Would you accept living in the same house as a person infected with HIV?

Not acceptable

Accept unwillingly

$32 \cdot 1$

Accept unconditionally

$14 \cdot 2$

$62 \cdot 9$

$30 \cdot 2$

Would you accept working in the same workplace as a person infected with HIV?

Not acceptable

$50 \cdot 0$

$23 \cdot 9$

$26 \cdot 1$

Accept unwillingly

$15 \cdot 5$

When you hear the word 'AIDS', which image do you have?

Death

$50 \cdot 4$

$51 \cdot 2$

Fear

$31 \cdot 7$

$32 \cdot 5$

Fever

$7 \cdot 2$

$11 \cdot 4$

Uncomfortable

$8 \cdot 6$

$2 \cdot 4$

No negative image

$1 \cdot 4$

Nothing particular

$0 \cdot 7$

0.8

$0 \cdot 8$ 
Table 2. Continued

Males (\%) Females (\%)

Do you have any experience of paying or getting money for sex? Yes

Do you have any experience of extramarital sexual intercourse? Yes

$66 \cdot 2$

$62 \cdot 5$

Did you use a condom when you last had sexual intercourse? Yes

mosquitoes or other biting insects?' and 'Is HIV transmitted by kissing?' were answered at a relatively lower rate of correctness, i.e. $53 \cdot 5 \%$ in females and $67 \cdot 8 \%$ in males, and $37 \cdot 8 \%$ in females and $67.9 \%$ in males, respectively. Of note is the large difference in knowledge level between female and male groups (Fig. 1). Other questions such as 'Do HIV-infected pregnant women have a risk of transmitting HIV to their children?', 'Does needle sharing have a risk of transmitting HIV?', 'Does STD increase the risk of transmitting HIV?', 'Is HIV transmitted by breast-feeding?' and 'Is HIV transmitted by sexual contact?' had relatively high correct-answer rates.

\section{Attitude towards HIVIAIDS}

Several questions were asked to determine respondents' attitude towards HIV/ AIDS, especially related to stigmatization and discrimination. First, basic questions about HIV/AIDS were asked: 'Do you know the word HIV?' and 'Do you know of anyone infected with HIV?' The answer rates were $94 \cdot 8 \%$ in males and $97 \cdot 4 \%$ in females, and $53.0 \%$ in males and $56.0 \%$ in females, respectively. To assess stigmatization or discrimination with regard to HIV/AIDS, questions were asked concerning acceptance of people living with HIV/AIDS. Only $14 \cdot 2 \%$ of males and $6.0 \%$ of females answered unconditionally that they would live in the same house as people infected with HIV, and a mere $26 \cdot 1 \%$ of males and $15 \cdot 5 \%$ of females said they would share the same work place as people infected HIV. In terms of the image of AIDS, the top two answers were 'death' and 'fear', which accounts for about $50 \%$ and $30 \%$, respectively. As for premarital sex, the percentages of respondents who answered that they 'disapprove' were $41.8 \%$ for males and $63.8 \%$ for females. Regarding the question 'In which ways did you learn about sexual matters?' about half of the respondents answered that they got information 'from friends' followed by 'lessons at school' $(17 \cdot 3 \%$ in males and $16 \cdot 0 \%$ in females), 'magazines' $(12 \cdot 7 \%$ in males and $10 \cdot 0 \%$ in females) and 'TV' (12.7\% in males and $8 \cdot 7 \%$ in females) (Table 2).

\section{Practice related to HIVIAIDS}

In order to understand practice related to HIV/AIDS, respondents were asked about their sexual activities. Questions asked were: 'Do you have any experience of 
$(\%)$

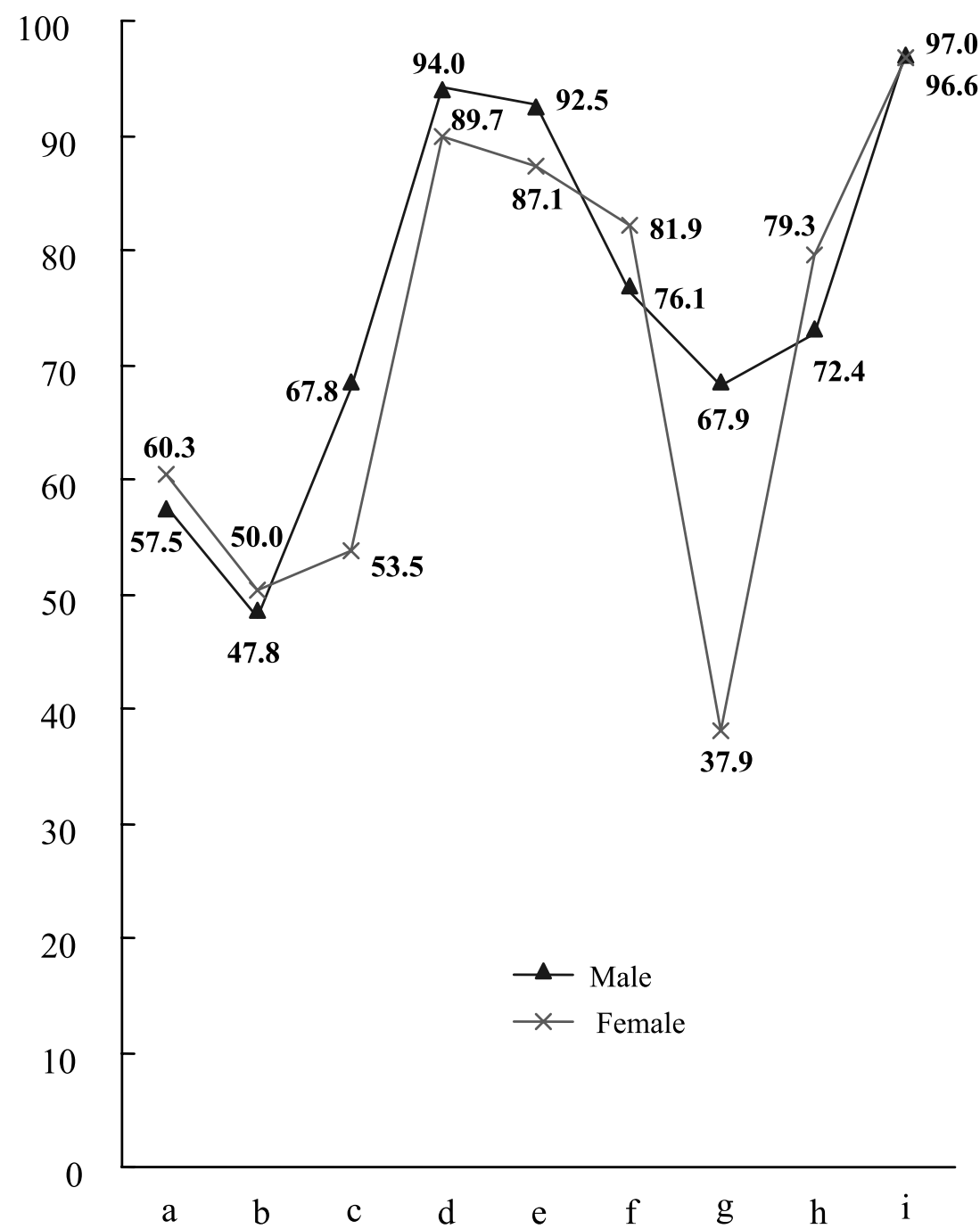

Fig. 1. The percentage of correct answers on HIV/AIDS knowledge. a: Might people infected with HIV look healthy? b: Is HIV antibodies testing useful for confirming diagnosis even after only one week of infection? c: Is HIV transmitted by mosquitoes or other biting insects? e: Does needle sharing have a risk of transmitting HIV? d: Do HIV-infected pregnant women have a risk of transmitting HIV to their children? f: Does STD increase the risk of transmitting HIV? g: Is HIV transmitted by kissing? h: Is HIV transmitted by breast-feeding? i: Is HIV transmitted by sexual contact?

paying or getting money for sex?', 'Do you have any experience of extramarital sex?' and 'Did you use a condom when you last had sexual intercourse?' $58 \cdot 6 \%$ of males and $73.4 \%$ of females had paid for or been paid for sex, and about two-thirds of 


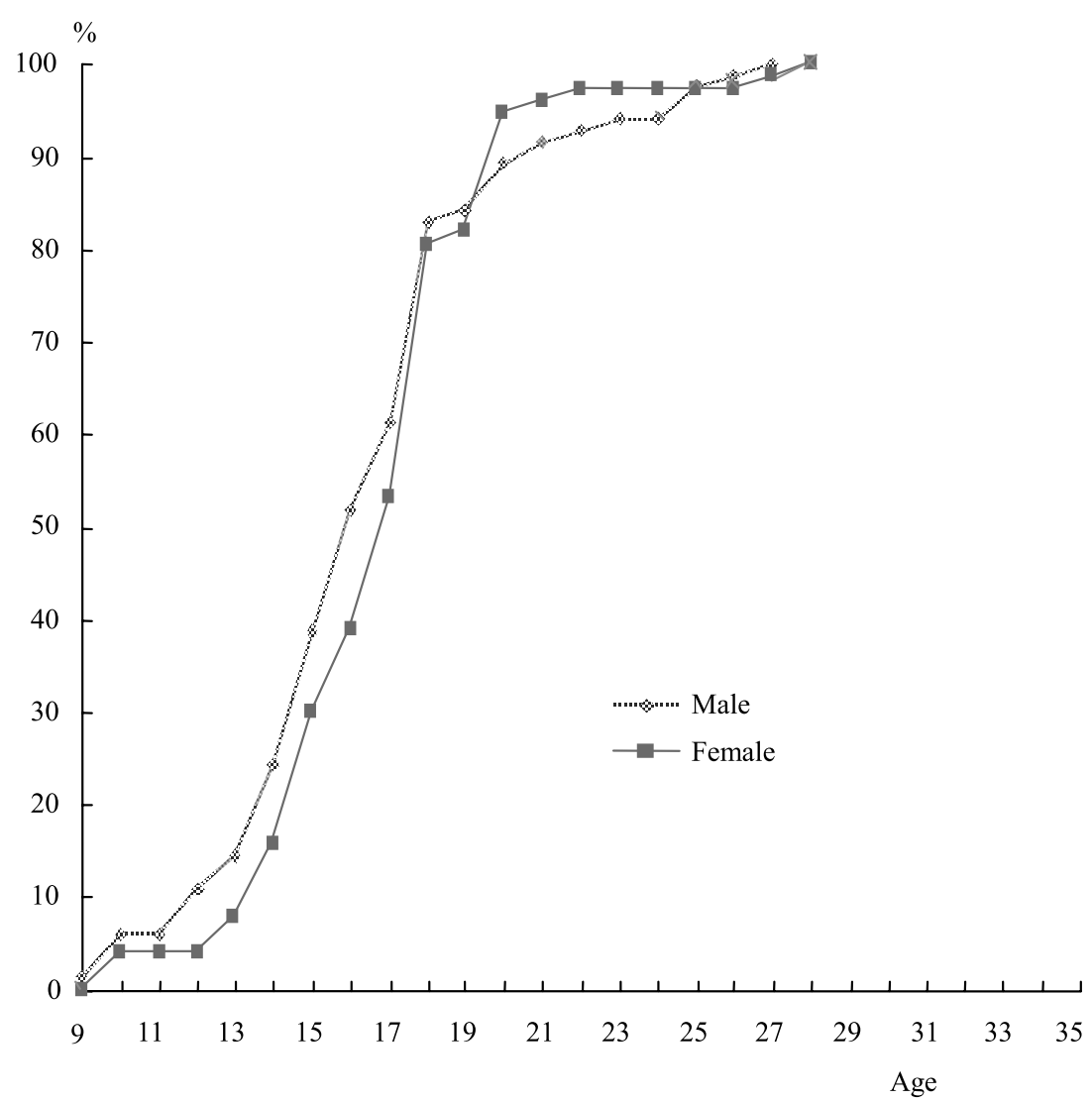

Fig. 2. The accumulate percentage of experience of sexual intercourse.

married respondents of both sexes had had out-of-marriage sexual intercourse (Table 2). The accumulated percentage of respondents with experience of sexual intercourse increased for both sexes constantly after 12-13 years of age (Fig. 2). More than half of the village population had had a sexual experience by 16 years of age in both sexes. The earliest case of first sexual intercourse was at 10 years of age. It is not clear whether there had been any coercion or sexual abuse forcing those who had an early sexual experience into sexual intercourse. The rates of sexual experiences among female teenagers were always higher than those of their male counterparts at the same age. Regarding sexual activity, the answer to the question 'How many partners have you ever had in your life?' showed two peaks in males but one peak in females (Table 3), indicating that some male respondents had had a fairly high number of sexual partners in their lifetime.

\section{Discussion}

This survey shows that almost everyone in this rural area of Kenya knew the word 'HIV', but only slightly more than half of the respondents said that they knew of 
Table 3. The number of sexual partners of respondents

\begin{tabular}{lcc}
\hline How many sexual partners have you had in your life? & Males & Females \\
\hline 1 & $23(29 \cdot 5 \%)$ & $42(56 \cdot 0 \%)$ \\
2 & $21(26 \cdot 9 \%)$ & $25(33 \cdot 3 \%)$ \\
3 & $4(5 \cdot 1 \%)$ & $3(4 \cdot 0 \%)$ \\
4 & $4(5 \cdot 1 \%)$ & $2(2 \cdot 7 \%)$ \\
5 & $6(7 \cdot 7 \%)$ & $2(2 \cdot 7 \%)$ \\
$6-10$ & $10(12 \cdot 8 \%)$ & $0(0 \%)$ \\
$>10$ & $15(19 \cdot 2 \%)$ & $3(4 \cdot 0 \%)$ \\
No answer & 50 & 39 \\
\hline
\end{tabular}

someone infected with HIV. The invisibility of early HIV infection is, of course, one reason for this, but the following possibilities cannot be discounted: (1) that there are people who do not declare their HIV status due to discrimination and stigmatization; (2) that there are many people who do not know their own HIV status. All things combined, nearly half of the people in the study community knew of at least one person infected with HIV in the region. The acceptance of living with HIV/AIDS by community members was not high, with more than $50 \%$ of respondents answering they would not accept living or working with people with HIV/AIDS under any circumstances. Near to the study site was an undertaker's shop displaying a poster with a picture of coffins and the word 'HIV'. Such an environment must make people feel that HIV/AIDS is a horrible thing. This survey showed that more than $50 \%$ of people gave their image of AIDS as 'death'.

The percentage of females who used a condom at their last sexual intercourse was low (just over half), and the percentage who paid or earned money for sex was high (over three-quarters). In Kenya, it is said that men are regarded as the 'first' gender and expect to be treated as such; women come 'second.' Women are not supposed to have a voice and if they do voice their opinions publicly, they open themselves up to insult. Such social norms might make women more vulnerable.

Almost half of respondents approved of premarital sex, but there is a slight difference between male and female respondents.

With regard to knowledge of HIV/AIDS, only two variables were statistically different between males and females: the association between kissing and HIV, and that between mosquito biting and HIV. The rate of correct answers for the questions about the association between STI and HIV, and breast-feeding and HIV was higher in females than in males, but the difference was not significant.

Considering that $43.4 \%$ of males and $50 \cdot 1 \%$ of females said that they learnt about sexual matters from their friends, $17 \cdot 3 \%$ of males and $16 \cdot 0 \%$ of females did so from lessons in school, and about one-tenth of males and females did so from TV or magazines, this suggest a strong influence of peers. So, a good way of imparting this information might be through peer education rather than one-way lectures.

With regard to sexual activity, $56.0 \%$ of females had only one partner in their life, whereas only $29 \cdot 5 \%$ of males had one partner in their life. Moreover, whereas $6 \cdot 7 \%$ 
of females responded they had had five or more partners in their life, $39 \cdot 7 \%$ of male responded they had had five or more partners. Of note, there is bimodal shape - two peaks - in males' but only one peak in females' responses to the question 'how many sexual partners have you had in your life', suggesting that some men have a large number of sexual partners in their lifetime.

Some researchers have suggested that those at high risk of HIV infection should be the target of HIV prevention intervention, including sexual education and promotion of safe sex, because those who have high sexual activity serve as a hub of the infection network (Parrado et al., 2004; Yamamoto et al., 2004). Furthermore, it might be important to start sexual education early in life, since first sexual intercourse was at around 12-13 years old in both sexes in this area (Fig. 2). In addition, since the sexual experiences of female teenagers were always greater than those of males of the same age, special attention should be paid to female teenagers when implementing sexual education.

The HIV/AIDS epidemic in Kenya is now in its third decade, yet it shows no sign of relenting. The degree of spread can be controlled by preventive and educational measures. Therefore, there is an urgent need to implement specific and focused HIV/AIDS prevention intervention in the Kenyan community.

\section{Acknowledgments}

The authors express their gratitude to their colleagues and the staff of the Kenya Medical Research Institute for supporting their research activities. The authors are very grateful to the local staff for their excellent technical assistance and to members of the local community for their participation.

\section{References}

Barker, G. (1993) Research on AIDS: knowledge, attitudes and practices among street youth. Child Worldwide 20(2-3), 41-2.

Kaimenyi, J. T. \& Ndung'u, F. L. (1994) Knowledge, practices and attitudes towards HIV positive and AIDS patients among dental auxiliaries. East African Medical Journal 71(5), 304-310.

Karani, A., Katsivo, K., Muhami, L. N., Lwafama, D. W. \& Ntsekhe, M. (1990) Knowledge, attitudes and practices on the acquired immune deficiency syndrome (AIDS) among health workers in (Nyeri), a district in Kenya. Kenya Nursing Journal 18(1), 28-30.

Katsivo, M. N. \& Muthami, L. N. (1991) Social characteristics and sexual behaviour of women at high risk of HIV infection in a town in Central Province of Kenya. East African Medical Journal 68(1), 34-38.

Mbago, M. C. \& Sichona, F. J. (2003) Correlates of knowledge of prevention of sexually transmitted diseases among primary school pupils in Tanzania. International Journal of STD and AIDS 14(9), 596-600.

Mbanya, D. N., Zebaze, R., Kengne, A. P., Minkoulou, E. M., Awah, P. \& Beure (2001) Knowledge, attitudes and practices of nursing staff in a rural hospital of Cameroon: how much does the health care provider know about the human immunodeficiency virus/acquired immune deficiency syndrome? International Nursing Review 48(4), 241-249.

NAPSCO (2000) AIDS in Kenya. National AIDS and STDs Control Program. 
Obudho, R. A. (1995) STDs, HIV, AIDS and urbanisation process in Kenya. African Journal of Health Sciences 2(1), 202-210.

Parrado, E. A., Flippen, C. A. \& McQuiston, C. (2004) Use of commercial sex workers among Hispanic migrants in North Carolina: implications for the spread of HIV. Perspectives on Sexual Reproduction and Health 36(4), 150-156.

Pattullo, A. L., Malonza, M., Kimani, G. G., Muthee, A., Otieno, P. A., Odhiambo, K., Moses, S. \& Plummer, F. A. (1994) Survey of knowledge, behaviour and attitudes relating to HIV infection and AIDS among Kenyan secondary school students. AIDS Care 6(2), 173-181.

Sindiga, I. \& Lukhando, M. (1993) Kenyan university students' views on AIDS. East African Medical Journal 70(11), 713-716.

UNAIDS \& WHO (2004) Aids Epidemic Update 2003.

Worldbank (1999) Confronting Aids: Public Priorities in a Global Epidemic. Oxford University Press, New York.

Yamamoto, T., Hamada, Y., Yawo Dotse, A., Ataka, Y. \& Moji, K. (2004) A simulation sheds a light on the present HIV epidemic. Tropical Medicine and Health 32(3), 249-251. 